\title{
The Role of Optimism in Stress and Coping of
}

\section{Undergraduate Students in Goa}

\author{
Brian Pacheco ${ }^{1}$, Dr. Shanmukh V. Kamble ${ }^{2}$
}

\section{ABSTRACT}

The present study was designed to study the relationship between optimism, stress and coping with stress. The sample for the study comprised of 500 undergraduate students from colleges in Goa. Three measures - 'Life Orientation Test-Revised' by Scheier \& Carver (1994), 'Perceived Stress Scale' by Cohen, Kamarck, \& Mermelstein (1983), and 'COPE' by Carver, Scheier, \& Weintraub (1989) were administered to participants. The findings of the research indicate a moderate negative relationship between optimism and stress. Optimism was found to be positively related to positive reinterpretation and growth, use of instrumental social support, active coping, acceptance, suppression of competing activities, and planning, and negatively related to mental disengagement, behavioural disengagement, focus on and venting of emotions, denial, and religious coping.

Keywords: Optimism, Stress, Coping.

College life is often mixed bag for students. While it provides students with ample opportunities to develop themselves, it also brings along stress of having to cope with various new challenges that they are exposed to. The manner in which students cope with stressors will differ from individual to individual, and would depend on several factors. Among these factors are the student's cognitions about life, more specifically, their expectations for the future-whether they, in general, expect to be successful in their endeavours or whether they anticipate failure. The former is referred to as 'optimism', and the latter as pessimism.

\section{Optimism}

Expectancy-value theories of motivation are based on the assumption that behaviour is organized around the pursuit of goals (Austin \& Vancouver, 1996; Carver \& Scheier, 1998). Goals are states or actions that people view as either desirable or undesirable. People try to modify their

\footnotetext{
${ }^{1}$ Research Scholar, Department of Psychology Karnatak University-Dharwad, Karnatak-India

2 Associate Professor, Department of Psychology Karnatak University-Dharwad, Karnatak-India

*Responding Author

(C) 2016 I B Pacheco, S Kamble; licensee IJIP. This is an Open Access Research distributed under the terms of the Creative Commons Attribution License (http://creativecommons.org/licenses/by/2.0), which permits unrestricted use, distribution, and reproduction in any Medium, provided the original work is properly cited.
} 
behaviours and themselves to seek what they desire while trying to avoid what they see as undesirable. The more important a goal is to someone, the greater is its value within the person's motivation. The second conceptual element in expectancy-value theories is expectancy-a sense of confidence or doubt about the attainability of the goal value. Only if people have enough confidence will they move into action and continue their efforts.

Expectancy-based theories generally suggest that behaviour is predicted best when the level of the expectancy fits that of the behaviour that is being predicted. When confronting a challenge optimists tend to take a posture of confidence and persistence (even if progress is difficult or slow). Pessimists tend be doubtful and hesitant. This divergence may even be amplified under conditions of serious adversity. Optimists are likely to assume that the adversity can be handled successfully, in one fashion or another. Pessimists are likely to anticipate disaster. These differences in how people approach adversity have important implications for the manner in which people cope with stress (Scheier \& Carver, 1992).

Two main approaches to the measurement of optimism have been taken and these are based on distinct conceptualisations of optimism (Peterson, 2000). At one extreme optimism has been conceptualised as a broad personality trait characterised by general optimistic expectations which is referred to as 'dispositional optimism' (Scheier \& Carver, 1985) while at the other it has been construed as an 'explanatory style' (Seligman, 1998).

The dispositional optimism approach asks people to indicate the extent to which they believe that their future outcomes will be good or bad (Scheier \& Carver, 1992). Expectancies that are generalized - expectancies that pertain more or less to the person's entire life space-are what are described as optimism and pessimism. People actually range from the very optimistic to the very pessimistic, with most falling somewhere in the middle. This approach views optimism as a trait and therefore, terms it dispositional optimism. Scheier and Carver define dispositional optimism as a global expectation that the future will bring a bounty of good things and a scarcity of bad things. In contrast, pessimism is the expectation that the future will bring more bad than good outcomes.

Another approach to optimism relies on the assumption that people's expectancies for the future derive from their view of the causes of events in the past (Peterson \& Seligman, 1984; Seligman, 1991). Seligman and his colleagues conceptualized optimism and pessimism in terms of explanatory style, that is, the characteristic way of explaining negative events (Peterson, 2000; Reivich \& Gillham, 2003; Seligman, 1990). If explanations for past failures focus on causes that are stable (rather than unstable), global (rather than specific), and internal (rather than external), person's expectancy for the future in the same domain will be for bad outcomes since he or she views the cause as relatively permanent (stable), affecting almost everything about a person's life (global), and stemming from the traits and beliefs of the individual rather than external circumstances (internal). 


\section{Stress}

The term stress has typically been used to refer both to the adjustive demands placed on an organism and to the organism's internal biological and psychological responses to such demands. Stress is a by-product of poor or inadequate coping. Adjustive demands, or the stressors, stem from resources that fall into three basic categories; frustrations, conflicts, and pressures. A wide range of obstacles, both external and internal, can lead to frustration. Frustrations can be particularly difficult for a person to cope with because they often lead to self-devaluation, making the person feel that she or he has failed in some way or is incompetent. In many instances, stress results from the simultaneous occurrence of two or more incompatible needs or motives where the requirements of one preclude satisfaction of the others. Pressures force us to speed up, redouble our effort, or change the direction of goal-oriented behaviour, which can seriously tax our coping resources or even lead to maladaptive behaviour (Carson, Butcher, Mineka, \& Hooley, 2008).

\section{Coping with Stress}

Inner factors such as a person's frame of reference, motives, competencies, or stress tolerance play the dominant role in determining his or her coping strategies. Richard Lazarus developed and tested a transactional theory of stress and coping (TTSC) (Lazarus, 1966; Lazarus \& Folkman, 1984). Lazarus (1966) contended that stress did not exist in the event but rather is a result of a transaction between a person and his or her environment. As such, stress encompasses a set of cognitive, affective, and coping factors.

In 1966, Lazarus identified two forms of coping: direct action and palliative. In 1984, Lazarus and Folkman changed the names of these two forms to problem-focused and emotion-focused, respectively. Problem-focused coping strategies are similar to problem-solving tactics. These strategies encompass efforts to define the problem, generate alternative solutions, weigh the costs and benefits of various actions, take actions to change what is changeable, and, if necessary, learn new skills. Emotion-focused coping strategies are directed toward decreasing emotional distress. These tactics include such efforts as distancing, avoiding, selective attention, blaming, minimizing, wishful thinking, venting emotions, seeking social support, exercising, and meditating.

Carver, Scheier and Weintraub (1989) set out to develop a measure of coping based on the Lazarus model of stress and their previous research (Carver \& Scheier, 1981, 1988; Scheier \& Carver, 1983, 1985). The COPE is made up of the following scales:

(i) Active coping: Taking action, exerting efforts, to remove or circumvent the stressor.

(ii) Planning: Thinking about how to confront the stressor, planning ones active coping efforts.

(iii) Seeking Instrumental Social Support: Seeking assistance, information, or advice about what to do. 
(iv) Seeking Emotional Social Support: Getting sympathy or emotional support from someone.

(v) Suppression of Competing Activities: Suppressing one's attention to other activities in which one might engage in order to concentrate more completely on dealing with the stressor.

(vi) Religion: Increased engagement in religious activities.

(vii) Positive Reinterpretation and Growth: Making the best of the situation by growing from it, or viewing it in a more favourable light.

(viii) Restraint Coping: Coping passively by holding back one's coping attempts until they can be of use.

(ix) Acceptance: Accepting the fact that the stressful event has occurred and is real.

(x) Focus on and Venting of Emotions: An increased awareness of one's emotional distress, and a concomitant tendency to ventilate or discharge those feelings.

(xi) Denial: An attempt to reject the reality of the stressful event.

(xii) Mental Disengagement: Psychological disengagement from the goal with which the stressor is interfering, through daydreaming, sleep, or self-distraction.

(xiii) Behavioural Disengagement: Giving up, or withdrawing effort from, the attempt to attain the goal with which the stressor is interfering.

(xiv) Alcohol/Drug Use: Turning to the use of alcohol or other drugs as a way of disengaging from the stressor.

(xv) Humor: Making jokes about the stressor

Individual differences in optimism play an important role in the adjustment to stressful life events (Scheier, Carver, \& Bridges, 2001). Greater optimism has been found to be associated with less mood disturbance in response to a variety of stressors, including adjustment to law school (Segerstrom, Taylor, Kemeny, \& Fahey, 1998), breast cancer and coronary bypass surgery (Carver et al., 1993; Scheier et al., 1989), and exposure to SCUD missile attacks (Zeidner \& Hammer, 1992).

Scheier, Weintraub, and Carver (1986) found optimism to be related to problem-focused coping among college students, especially when the stressful situation was controllable. Optimism also related to the use of positive reframing and with the tendency to accept the situation's reality. In contrast, optimism related negatively to the use of denial and the attempt to distance oneself from the problem.

This research study sought to evaluate whether similar relationships hold true in the Indian context, more specifically in the context of the college student population. It aimed at verifying whether optimism is related to the level of stress experienced, and more effective of coping. The majority of studies conducted thus far, had explored the relationships between these variables among people who are undergoing truly serious crises rather than ordinary problems of daily life. 
Hence this research was intended at discovering whether these relationships also exist in cases where youth are faced with the stresses of academic life, more specifically in the Indian context.

\section{METHODOLOGY}

A correlation research design was used to investigate the relationship between Optimism, Stress and Coping in undergraduate students. The sample for the study comprised of 500 undergraduate students from Goa between the ages of $16-25$ (male = 254 and female $=246$ ). The students were chosen by random sampling. All participants received adequate information about the nature of the study and their consent was taken prior to participation in the study.

Three measures were used by the researcher: (a) 'Life Orientation Test - Revised' by Scheier \& Carver (1994) as a measure of Optimism. The LOTR (Scheier, Carver, \& Bridges, 1994) is a 10item scale, with four filler items and six scale items; (b) 'Perceived Stress Scale' by Cohen, Kamarck, \& Mermelstein (1983) as a measure of Stress: The PSS measures psychological stress experienced during the past month. Participants rate each of 10 items on a 5-point response scale ranging from 1 (never) to 5 (very often); and (c) 'COPE' by Carver, Scheier, \& Weintraub (1989) as a measure of Coping: The COPE is a 60-item multidimensional coping instrument designed to assess 15 conceptually distinct methods of coping. Participants are instructed to rate how often they engaged in the strategy described by each item when they encountered difficulties on a 4point Likert-type scale. The results obtained were analyzed using SPSS 22.

\section{RESULTS}

As is seen in table 1, a significant moderate negative correlation was found between optimism and stress $(\mathrm{r}=-.480, \mathrm{P}<0.01)$. These results indicate that students with higher levels of optimism reported lower level of stress, and vice versa.

Where coping with stress is concerned, Optimism showed weak positive relationships with the dimensions of Positive Reinterpretation and Growth $(\mathrm{r}=.278, \mathrm{P}<0.01)$, Use of Instrumental Social Support ( $\mathrm{r}=.110, \mathrm{P}<0.05)$, Active Coping ( $\mathrm{r}=.217, \mathrm{P}<0.01)$, Acceptance $(\mathrm{r}=.119, \mathrm{P}<0.01)$, Suppression of Competing Activities ( $\mathrm{r}=.091, \mathrm{P}<0.05)$, and Planning $(\mathrm{r}=.200, \mathrm{P}<0.01)$. Weak negative relationships were found between Optimism and the dimensions of Mental Disengagement ( $r=-.212, \mathrm{P}<0.01$ ), Focus on and Venting of Emotions ( $\mathrm{r}=-.108, \mathrm{P}<0.05)$, Denial ( $\mathrm{r}=-.234, \mathrm{P}<0.01$ ), Religious Coping ( $\mathrm{r}=-.121, \mathrm{P}<0.01$ ), and Behavioural Disengagement ( $\mathrm{r}=-$ $.278, \mathrm{P}<0.01)$. No significant relationships were found between Optimism and Humour, Restraint Coping, Seeking Emotional Social Support and Substance Abuse.

\section{DISCUSSION}

Previous findings on optimism have indicated that optimism is linked to lower levels of stress since optimistic individuals generally anticipate positive outcomes to their actions. Pessimists, on the hand, anticipate failure, and as a result tend to experience greater levels of stress. This study 
has found a moderate negative relationship between optimism and stress. Thus, participants with higher levels of optimism showed lower levels of stress.

The effects of optimism on stress have been found by various studies (Scheier, Weintraub, and Carver, 1986; Aspinwall and Taylor, 1992; Fontaine, Manstead, and Wagner, 1993) to be mediated by coping strategies employed by optimists to deal with stress. In this study, optimism was found to have weak positive relationships with the dimensions of positive reinterpretation and growth, use of instrumental social support, active coping, acceptance, suppression of competing activities, and planning. Some of these findings are in line with previous research. Scheier, Weintraub, and Carver (1986) have also reported a positive association between optimism and acceptance. Aspinwall and Taylor (1992) found that optimism is related to more effective, active coping. Fontaine, Manstead, and Wagner (1993) in their study on a sample of undergraduate students, found that optimism was positively correlated with active coping and positive reinterpretation. Harju and Bolen (1998) reported that high-level optimists in their study used the most action and reframing coping styles.

In this study, weak negative relationships were found between optimism and the dimensions of mental disengagement, behavioural disengagement, focus on and venting of emotions, denial, and religious coping. Some of these findings are also supported by previous studies. In their studies, Scheier, Weintraub, and Carver (1986) found that pessimism was associated with denial and distancing, with focusing on stressful feelings, and with disengagement from the goal with which the stressor was interfering. Fontaine, Manstead, and Wagner (1993) reported that optimism was negatively correlated with focusing on and venting of emotion. In the study by Harju and Bolen (1998), low-level optimists were found to use more alcohol and disengagement for coping.

The brighter outlook of life that optimists have appears to play a role in the effective coping with stress that optimists exhibit. Besides this, literature seems to advocate the view that optimism helps people pay attention to negative information, and thereby play an active role in coping with stressors. Aspinwall \& Brunhart (2000) based on their review of three studies focussing on processing of health-risk information suggest that optimists' ability to attend to and elaborate self-relevant negative information, in conjunction with their more active coping efforts, may explain some of the impressive prospective benefits of optimistic beliefs in coping with a wide range of stressors.

\section{CONCLUSION}

The current study confirms that optimism shares a similar relationship with stress and coping in the Indian context, as has been found in studies across the globe. Optimism was found to be linked to low levels of stress and more effective strategies of coping with stress, indicating that optimism plays a significant mediating role in coping with stress efficiently. 


\section{REFERENCES}

Aspinwall, L. G., \& Brunhart, S. M. (2000). What I do know won't hurt me: Optimism, attention to negative information, coping, and health. In The science of optimism and hope: Research essays in honor of Martin E P Seligman (pp. 163-200).

Aspinwall, L. G., \& Taylor, S. E. (1992). Modeling cognitive adaptation: a longitudinal investigation of the impact of individual differences and coping on college adjustment and performance. Journal of Personality and Social Psychology, 63(6), 989-1003. http://doi.org/10.1037/0022-3514.63.6.989

Austin, J. T., \& Vancouver, J. B. (1996). Goal constructs in psychology: Structure, process, and content. Psychological Bulletin, 120, 338-375.

Carson, R. C., Butcher, J. N., Mineka, S., \& Hooley, J. M. (2008). Abnormal psychology.(13th ed.). India: Dorling Kindersley.

Carver, C. S., \& Scheier, M. F. (1981). Self-consciousness and reactance. Journal of Research in Personality, 15(1), 16-29.

Carver, C. S., \& Scheier, M. F. (1988). A control-process perspective on anxiety. Anxiety Research, 1(1), 17-22.

Carver, C. S., \& Scheier, M. F. (1998). On the self-regulation of behavior. New York: Cambridge University Press.

Carver, C. S., Pozo, C., Harris, S. D., Noriega, V., Scheier, M. F., Robinson, D. S., ... Clark, K. C. (1993). How coping mediates the effect of optimism on distress: a study of women with early stage breast cancer. Journal of Personality and Social Psychology, 65(2), 375390. http://doi.org/10.1037/0022-3514.65.2.375

Carver, C. S., Scheier, M. F., \& Weintraub, J. K. (1989). Assessing coping strategies: a theoretically based approach. Journal of Personality and Social Psychology, 56(2), 267283. doi:10.1037/0022-3514.56.2.267

Cohen, S., Kamarck, T., \& Mermelstein, R. (1983). A global measure of perceived stress. Journal of Health and Social Behavior, 24(4), 385-396. http://doi.org/10.2307/2136404

Fontaine, K. R., Manstead, A. S. R. and Wagner, H. (1993), Optimism, perceived control over stress, and coping. European Journal of Personality, 7, 267-281. doi: 10.1002/per.2410070407

Harju, B., \& Bolen, L. (1998). The Effects of Optimism on Coping and perceived quality of life of college students. Journal of Social Behavior \& Personality, 13(2), 185-200. Retrieved from http://psycnet.apa.org/psycinfo/1998-10358-001

Lazarus, R. S. (1966). Psychological stress and the coping process. New York, NY: McGrawHill.

Lazarus, R. S., \& Folkman, S. (1984). Stress. Appraisal, and coping, 725.

Peterson, C. (2000). The future of optimism. American Psychologist, 55(1), 44-55. http://doi.org/10.1037//0003-066X.55.1.44

Peterson, C., \& Seligman, M. E. P. (1984). Causal explanations as a risk factor for depression: Theory and evidence. Psychological Review, 91, 347-374. 
Reivich, K. \& Gillham, J. (2003). Learned optimism: The measurement of explanatory style. In S. J. Lopez \& C. R. Snyder (Eds.) Positive psychological assessment: A handbook of models and measures (pp. 57-74). Washington, DC: American Psychological Association.

Scheier, M. and Carver, C. (1985). Optimism, coping and health: assessment and implications of generalized outcome expectancies. Health Psychology, 4:219-47.

Scheier, M. F., \& Carver, C. S. (1983). Self-directed attention and the comparison of self with standards. Journal of Experimental Social Psychology, 19(3), 205-222.

Scheier, M. F., \& Carver, C. S. (1985). Optimism, coping, and health: assessment and implications of generalized outcome expectancies. Health psychology, 4(3), 219.

Scheier, M. F., \& Carver, C. S. (1992). Effects of optimism on psychological and physical wellbeing: Theoretical overview and empirical update. Cognitive Therapy and Research, 16(2), 201-228. http://doi.org/10.1007/BF01173489

Scheier, M. F., Carver, C. S., \& Bridges, M. W. (1994). Distinguishing optimism from neuroticism (and trait anxiety, self-mastery, and self-esteem): a reevaluation of the Life Orientation Test. Journal of Personality and Social Psychology, 67(6), 1063-1078. http://doi.org/10.1037/0022-3514.67.6.1063

Scheier, M. F., Carver, C. S., \& Bridges, M. W. (2001). Optimism, pessimism, and psychological well-being. In E. C. Chang (Ed.), Optimism and pessimism: Implications for theory, research, and practice (pp. 189-216). Washington, DC: American Psychological Association.

Scheier, M. F., Matthews, K. A., Owens, J. F., Magovern, G. L., Lefbvre, R. C., Abbott, R. R., \& Carver, C. S. (1989). Dispositional optimism and recovery from coronary artery bypass surgery. The beneficial effects on physical and psychological well-being. Journal of Personality and Social Psychology, 57, 1024-1040.

Scheier, M. F., Weintraub, J. K., \& Carver, C. S. (1986). Coping with stress: divergent strategies of optimists and pessimists. Journal of Personality and Social Psychology, 51(6), 12571264. http://doi.org/10.1037/0022-3514.51.6.1257

Segerstrom, S. C., Taylor, S. E., Kemeny, M. E., \& Fahey, J. L. (1998). Optimism is associated with mood, coping and immune change in response to stress. Journal of Personality and Social Psychology, 74, 1646-1655.

Seligman, M. (1998). Learned Optimism: How to Change Your Mind and Your Life (2nd edn). New York: Pocket Books.

Seligman, M. E. P. (1991). Learned optimism. New York: Knopf.

Seligman, M. E. P. (1990). Learned optimism. New York: Pocket Books.

Zeidner, M., \& Hammer, A. L. (1992). Coping with missile attack: Resources, strategies, and outcomes. Journal of Personality, 60, 709-746. 
Table 1: Table showing Pearson's correlation coefficient of the Optimism, Stress and Coping of undergraduate students $(N=500)$.

\begin{tabular}{|c|c|c|c|c|c|c|c|c|c|c|c|c|c|c|c|c|c|}
\hline & $\begin{array}{c}\text { Optim } \\
\text { ism }\end{array}$ & Stress & PRG & MD & FVE & ISS & AC & D & RelC & $\mathbf{H}$ & BD & ResC & ESS & SU & A & SCA & $\mathbf{P}$ \\
\hline Optimism & 1 & $\begin{array}{c}- \\
.480^{* *} \\
\end{array}$ & $.278^{* *}$ & $\begin{array}{c}- \\
.121^{* *}\end{array}$ & $-.108^{*}$ & $.110^{*}$ & $.217^{* *}$ & $\begin{array}{c}- \\
.234^{* *} \\
\end{array}$ & $-.121^{* *}$ & .020 & $-.278^{* *}$ & .083 & -.057 & -.080 & $.119^{* *}$ & $.091^{*}$ & $.200^{* *}$ \\
\hline Stress & $-.480^{* *}$ & 1 & $-.281^{* *}$ & $.234^{* *}$ & $.309^{* *}$ & -.027 & $-.188^{* *}$ & $.244^{* *}$ & $.190^{* *}$ & -.085 & $.280^{* *}$ & -.054 & $.131^{* *}$ & .032 & $-.144^{* *}$ & .008 & $-.207^{* *}$ \\
\hline PRG & $.278^{* *}$ & $-.281^{* *}$ & 1 & .061 & .059 & $.431^{* *}$ & $.511^{* *}$ & -.085 & $.158^{* *}$ & $.092^{*}$ & $-.186^{* *}$ & $.339^{* *}$ & $.153^{* *}$ & $-.161^{* *}$ & $.416^{* *}$ & $.325^{* *}$ & $.523^{* *}$ \\
\hline MD & $-.212^{* *}$ & $.234^{* *}$ & .061 & 1 & $.249^{* *}$ & .020 & -.062 & $.241^{* *}$ & $.151^{* *}$ & $.202^{* *}$ & $.277^{* *}$ & .079 & $.156^{* *}$ & .058 & .015 & $.091^{*}$ & -.020 \\
\hline FVE & $-.108^{*}$ & $.309^{* *}$ & .059 & $.249^{* *}$ & 1 & $.337^{* *}$ & .076 & $.204^{* *}$ & $.383^{* *}$ & .012 & $.267^{* *}$ & $.136^{* *}$ & $.518^{* *}$ & -.086 & $.134^{* *}$ & $.220^{* *}$ & $.122^{* *}$ \\
\hline ISS & $.110^{*}$ & -.027 & $.431^{* *}$ & .020 & $.337^{* *}$ & 1 & $.406^{* *}$ & .035 & $.217^{* *}$ & .078 & .051 & $.266^{* *}$ & $.549^{* *}$ & $-.178^{* *}$ & $.242^{* *}$ & $.296^{* *}$ & $.335^{* *}$ \\
\hline AC & $.217^{* *}$ & $-.188^{* *}$ & $.511^{* *}$ & -.062 & .076 & $.406^{* *}$ & 1 & -.064 & $.097^{*}$ & .079 & $-.169^{* *}$ & $.281^{* *}$ & $.132^{* *}$ & $-.220^{* *}$ & $.331^{* *}$ & $.390^{* *}$ & $.557^{* *}$ \\
\hline D & $-.234^{* *}$ & $.244^{* *}$ & -.085 & $.241^{* *}$ & $.204^{* *}$ & .035 & -.064 & 1 & $.286^{* *}$ & $.219^{* *}$ & $.476^{* *}$ & $.171^{* *}$ & $.166^{* *}$ & .081 & -.061 & $.166^{* *}$ & -.060 \\
\hline RelC & $-.121^{* *}$ & $.190^{* *}$ & $.158^{* *}$ & $.151^{* *}$ & $.383^{* *}$ & $.217^{* *}$ & $.097^{*}$ & $.286^{* *}$ & 1 & .010 & $.256^{* *}$ & $.252^{* *}$ & $.290^{* *}$ & $-.089^{*}$ & .075 & $.218^{* *}$ & $.123^{* *}$ \\
\hline $\mathbf{H}$ & .020 & -.085 & $.092^{*}$ & $.202^{* *}$ & .012 & .078 & .079 & $.219^{* *}$ & .010 & 1 & $.177^{* *}$ & $.116^{* *}$ & .015 & $.099^{*}$ & $.226^{* *}$ & $.090^{*}$ & $.098^{*}$ \\
\hline BD & $-.278^{* *}$ & $.280^{* *}$ & $-.186^{* *}$ & $.277^{* *}$ & $.267^{* *}$ & .051 & $-.169^{* *}$ & $.476^{* *}$ & $.256^{* *}$ & $.177^{* *}$ & 1 & $.107^{*}$ & $.205^{* *}$ & $.251^{* *}$ & -.039 & .036 & $-.111^{*}$ \\
\hline ResC & .083 & -.054 & $.339^{* *}$ & .079 & $.136^{* *}$ & $.266^{* *}$ & $.281^{* *}$ & $.171^{* *}$ & $.252^{* *}$ & $.116^{* *}$ & $.107^{*}$ & 1 & $.174^{* *}$ & -.011 & $.340^{* *}$ & $.349^{* *}$ & $.272^{* *}$ \\
\hline ESS & -.057 & $.131^{* *}$ & $.153^{* *}$ & $.156^{* *}$ & $.518^{* *}$ & $.549^{* *}$ & $.132^{* *}$ & $.166^{* *}$ & $.290^{* *}$ & .015 & $.205^{* *}$ & $.174^{* *}$ & 1 & .002 & .078 & $.188^{* *}$ & $.107^{*}$ \\
\hline SU & -.080 & .032 & $-.161^{* *}$ & .058 & -.086 & $-.178^{* *}$ & $-.220^{* *}$ & .081 & $-.089^{*}$ & $.099^{*}$ & $.251^{* *}$ & -.011 & .002 & 1 & .005 & $-.156^{* *}$ & $-.134^{* *}$ \\
\hline A & $.119^{* *}$ & $-.144^{* *}$ & $.416^{* *}$ & .015 & $.134^{* *}$ & $.242^{* *}$ & $.331^{* *}$ & -.061 & .075 & $.226^{* *}$ & -.039 & $.340^{* *}$ & .078 & .005 & 1 & $.243^{* *}$ & $.415^{* *}$ \\
\hline SCA & $.091^{*}$ & .008 & $.325^{* *}$ & $.091^{*}$ & $.220^{* *}$ & $.296^{* *}$ & $.390^{* *}$ & $.166^{* *}$ & $.218^{* *}$ & $.090^{*}$ & .036 & $.349^{* *}$ & $.188^{* *}$ & $-.156^{* *}$ & $.243^{* *}$ & 1 & $.390^{* *}$ \\
\hline $\mathbf{P}$ & $.200^{* *}$ & $-.207^{* *}$ & $.523^{* *}$ & -.020 & $.122^{* *}$ & $.335^{* *}$ & $.557^{* *}$ & -.060 & $.123^{* *}$ & $.098^{*}$ & $-.111^{*}$ & $.272^{* *}$ & $.107^{*}$ & $-.134^{* *}$ & $.415^{* *}$ & $.390^{* *}$ & 1 \\
\hline
\end{tabular}

**. Correlation is significant at the 0.01 level (2-tailed). * . Correlation is significant at the 0.05 level (2-tailed).

[Short forms used: PRG = Positive Reinterpretation and Growth, $\mathbf{M D}=$ Mental Disengagement, FVE $=$ Focus on and Venting of Emotions, ISS $=$ Use of instrumental social support, AC $=$ Active coping, $\mathbf{D}=$ Denial, RelC = Religious coping, $\mathbf{H}=$ Humour, $\mathbf{B D}=$ Behavioral Disengagement, $\mathbf{R e s C}=$ Restraint Coping, ESS $=$ Seeking Emotional Social Support, SU s= Substance use, $\mathbf{A}=$ Acceptance, SCA = Suppression of Competing Activities, and $\mathbf{P}=$ Planning.] 